\title{
Urinary excretion of adrenaline and noradrenaline in lumberjacks with vibration syndrome
}

\author{
H UNE, H ESAKI \\ From the Department of Hygiene, School of Medicine, Fukuoka University, Fukuoka, Japan
}

The vibration syndrome includes vibration induced white finger and disturbances of the peripheral nerves, muscles, bones, and joints. ${ }^{1-3}$ The pathophysiology of the disturbance of the peripheral circulation is not completely understood, however. It has been hypothesised that workers with vibration syndrome have overactivity of the sympathoadrenal system and that this may play a part in the aetiology $\mathrm{y}^{4}$; there have, however, been few studies to verify this hypothesis.

The purpose of the present study was to determine whether activity of the sympathoadrenal system is increased in lumberjacks with vibration syndrome, using urinary excretion of adrenaline and noradrenaline as an index. ${ }^{67}$

\section{Subjects and methods}

\section{SUBJECTS}

Twenty two lumberjacks with vibration syndrome voluntarily took part in this study. The mean duration of their chainsaw use was 16.7 years (8-26 years); their mean age was 55.8 years (48-63). They stopped using chainsaws when they received financial compensation for vibration syndrome. They all had Raynaud's phenomenon and numbness, tingling, coolness, joint pain in the hands, and palmar sweating but not hypertension.

Twenty two age matched ( \pm 5 years) referents were selected from healthy deskworkers; their mean age was $55 \cdot 5$ years $(48-66)$.

\section{METHODS}

Twenty four hour urine collections were made in January on the same day for each pair. The urinary excretion of total adrenaline and total noradrenaline was measured using a fluorimetric method ${ }^{8}$ and these concentrations were adjusted for urinary creatinine. Both the cases and the referents stopped working, doing sports, driving, and drinking alcohol and coffee during the 24 hours of the urine collection.

Statistical significance levels were determined by $t$

Accepted 14 August 1987 test. Since logarithmic transformations rather than absolute values followed a normal distribution, logarithmic transformations were used for statistical analysis.

\section{Results}

The figure shows distributions of the urinary excretion of total adrenaline and noradrenaline. The geometric mean of adrenaline excretion was $5.4 \mu \mathrm{g} /$ day in the cases and $5.5 \mu \mathrm{g} /$ day in the referents. The geometric mean of noradrenaline excretion was $55.7 \mu \mathrm{g} /$ day in the cases and $39.1 \mu \mathrm{g} / \mathrm{day}$ in the referents. No significant difference was observed in adrenaline excretion between the two groups but the cases excreted significantly more noradrenaline excretion than the referents $(\mathrm{p}<0.05)$.

\section{Discussion}

Our study was undertaken to investigate the hypothesis that workers with vibration syndrome have an
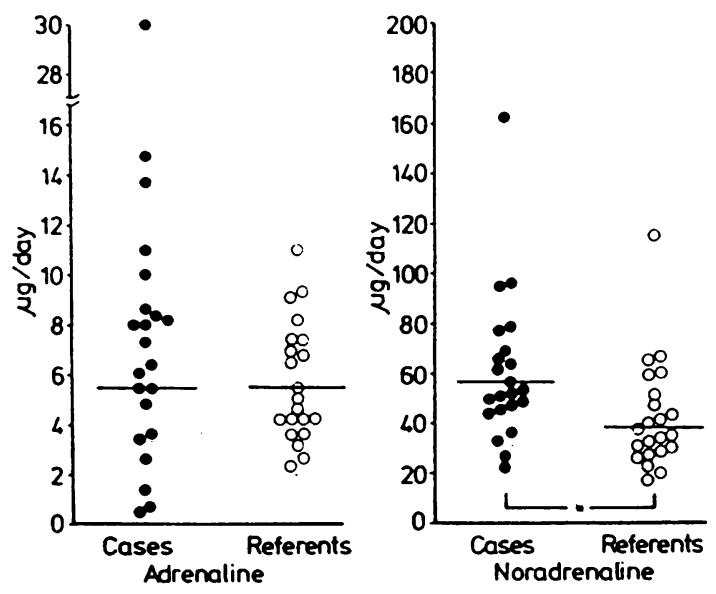

Urinary excretion of adrenaline and noradrenaline. Geometric mean values for each group are indicated by horizontal line. ${ }^{*} p<0.05$. 
overactivity of the sympathoadrenal system which may play a part in the aetiology of the disturbance of the peripheral circulation.

The cases excreted significantly more noradrenaline than the referents. Since most noradrenaline is secreted from the sympathetic nerve endings, ${ }^{7}$ our findings suggest that the cases have an overactivity of the sympathetic nervous system in winter, the period when the study was conducted, and support the hypothesis.

Some studies have investigated the urinary excretion of catecholamines in workers with vibration syndrome in eastern Europe ${ }^{9-11}$ but the results were inconsistent. Krasavina et $a l^{9}$ and Vinarik observed increased adrenaline and decreased noradrenaline excretion in diurnal urine among patients with the vibration syndrome. ${ }^{910}$ On the other hand, Lutai reported that such patients had increased excretion of both substances in diurnal urine."

Azuma et al showed experimentally that the responsiveness of arterial smooth muscle to noradrenaline was raised after the imposition of vibratory stimulation. ${ }^{5}$ This finding, together with our results, suggests that in the vibration syndrome peripheral vasoconstriction may be increased in combination with an overactivity of the sympathetic nervous system and hyper-responsiveness of arterial smooth muscle to noradrenaline. Our results would thus explain the peripheral circulatory changes in the vibration syndrome.

Although the mechanism which causes overactivity of the sympathetic nervous system is unknown, Matoba et al suggested that vibration, noise, and cold in the environment excite the hypothalamus and the limbic lobe of the cerebral cortex and produce a disorder of the central autonomic nervous system which may be related to the occurrence of Raynaud's phenomenon. ${ }^{1213}$

Physical activity, mental stress, environmental factors such as cold and noise, caffeine, smoking, and age all cause an increased excretion of catecholamines. ${ }^{67}$ These are confounding factors. Age was matched for and drinking coffee and alcohol was stopped during this study. The cases and the referents were also given advice intended to reduce the effect of some of the other factors. If there were any differences between the two groups the cases may have had less physical activity and less stress from environmental factors because the cases were under our control but the referents were not. The cases also smoked less. Although the level of mental stress between the two groups was unknown, mental stress produces a greater secretion of adrenaline than of noradrenaline. ${ }^{14}$

Our study determined the level of activity of the sympathoadrenal system at rest in winter in lumberjacks with the vibration syndrome. In future studies it would be of interest to investigate the activity of the sympathoadrenal system during a manifestation of Raynaud's phenomenon. Such a study would make the pathophysiology of the changes in the peripheral circulation clearer.

Requests for reprints to: Dr H Une, Department of Hygiene, School of Medicine, Fukuoka University, 745-1 Nanakuma, Jonan-ku, Fukuoka 814-01, Japan.

\section{References}

1 Matoba T, Kusumoto H, Takamastu M. A new criterion of the severity of the vibration disease. Japanese Journal of Industrial Health 1975;17:211-4.

2 Futatsuka $M$, Ueno $T$. Vibration exposure and vibration-induced white finger due to chain saw operation. J Occup Med 1985;27:257-64.

3 Dupuis $H$, Gemne G. Hand-arm vibration and the central nervous system. Report from an international symposium. Int Arch Occup Environ Health 1985;55:185-9.

4 Nasu Y, Shingu H, Kishikawa H. Urinary excretion and blood concentration of catecholamine in patients with vibration syndrome. Japanese Journal of Traumatology and Occupational Medicine 1975;23:267-74.

5 Azuma T, Ohhashi T, Sakaguchi M. Vibration-induced hyperresponsiveness of arterial smooth muscle to noradrenaline with special reference to Raynaud's phenomenon in vibration disease. Cardiovasc Res 1978;12:758-64.

6 Levi L. Methodological considerations in psychoendocrine research. Acta Med Scand (suppl) 1972;528:28-54.

7 Ziegler MG, Lake CR, eds. Norepinephrine. London: Williams \& Wilkins, 1984:1-26.

8 Iwamoto T, Yoshiura M, Ozaki Y, Iriyama K. Re-examination of an alumina procedure for the preliminary purification of urinary catecholamines. Jikeikai Medical Journal 1982;29:36171.

9 Krasavina TS, Volkova TN, Gornik VM. Functional condition of the sympatho-adrenal system in patients with late stages of vibration disease. Klin Med (Mosk) 1977;55:77-80.

10 Vinarik EM. Neuroendocrinous changes in vibration-noise disease in Donbass miners. Vrach Delo 1973;10:133-5.

11 Lutai AB. Condition of catecholamine metabolism in patients with vibration disease. Gig Tr Prof Zabol 1971;15:45-8.

12 Matoba T, Kusumoto H, Kuwahara $\mathrm{H}$, et al. Pathophysiology of vibration disease. Japanese Journal of Industrial Health 1975;17:11-8.

13 Matoba T, Kusumoto H, Mizuki Y, Kuwahara H, Inanaga K, Takamastu M. Clinical features and laboratory findings of vibration disease: a review of 300 cases. Tohoku J Exp Med 1977;123:57-65.

14 Jenner DA, Reynolds V, Harrison GA. Catecholamine excretion rates and occupation. Ergonomics 1980;23:237-46. 